\title{
Redesigning a 20th century regulatory framework to deliver 21st century energy technology
}

\author{
Tim Nelson* \\ Level 21, 101 Miller Street \\ North Sydney, NSW, 2060 \\ December 2015
}

\begin{abstract}
Electricity systems are shifting from a once highly centralised regulated model to become more distributed and consumer-centric. Australia has some of the highest installation rates of embedded renewable electricity generation in the developed world. This has been driven by increasing grid-supplied energy prices, policy incentives and declining technology costs. The emergence of cost-effective distributed battery storage and energy management systems is likely to fundamentally alter the electricity industry - which has been largely unchanged for decades. Evolutionary economics indicates that firms must adapt to new technologies and market conditions or they will become extinct. Energy markets will only evolve, however, if regulatory frameworks continuously adapt to ensure that consumer preferences for reliability, control and environmental outcomes are able to be achieved at lowest cost. Most importantly, regulators will need to ensure that facilitating efficient consumer decision making is prioritised.
\end{abstract}

Keywords: regulatory frameworks; electricity; solar; battery storage JEL Codes: D04, D47, Q40, Q41, Q48

\section{Introduction}

Australia has been at the forefront of distributed electricity generation adoption. Since 2008, the cost of installing embedded solar PV has declined by around 80\% (Simshauser, 2014). In some Australian jurisdictions, around one in five residential properties is now operating its own distributed generation. At the same time, the CSIRO (reported in AEMC, 2015, p. 6) estimates that battery technology costs will decline by between 53-85 percent over the next decade. Energy storage is predicted to reach around $2 \mathrm{GWh}$ in 2025 and $4 \mathrm{GWh}$ by 2035 - around $2 \%$ of system energy demand (depending upon the forecast scenario).

Within the National Electricity Market (NEM) on Australia's east-coast, South Australia is emerging as a global test-case of how to incorporate large volumes of renewable energy while maintaining system security given issues related to renewable intermittency. Total installed capacity of large-scale wind and distributed (i.e. household premise) solar in South Australia in 2014 were 1,085 MW and 410 MW respectively, in a system with peak demand of 3,282 MW, average load of 1,481 MW and a ratio of peak to underlying of around 2.4 (esaa, 2015). At times during 2014, wind generation alone was up to $109 \%$ of underlying South Australian electricity demand. At other times of peak demand, renewable generation was almost zero necessitating the use of ageing thermal power stations - Nelson, Reid and McNeill (2015) and Nelson (2015) provide further analysis of these issues. Only 15 years ago, the very same system had virtually no renewable energy produced within it. At the time of writing, there is much discussion about whether policy-makers should persist with the current 'energy-only' market design or consider alternatives, such as capacity markets. The situation in South Australia highlights what is increasingly facing policy makers around the world: how to ensure that previously highly regulated electricity markets are allowed to evolve as technologies change and improve. Specifically, incorporating large volumes of intermittent renewables and energy storage in a manner that is in the long-term interests of consumers. 
The CSIRO (2014) Future Grid Forum 2050 scenarios present four potential futures for the Australian electricity market. These are: set and forget (a continuation of the status quo); leaving the grid; rise of the prosumer; and centrally-controlled renewables thrive. Importantly, the CSIRO (2015) has stated that there are seven universal observations across these scenarios: a shift from network-centric to customer centric; moving from centralised to decentralised energy supply; continuous decarbonisation and greater electricity intermittency; removing regulated monopolies and increasing exposure to competition; $20-50 \%$ of localised support by 2050; continued use of the grid; and 2015-25 being characterised by profound transition. Nelson and McNeill (2016) and CSIRO (2015) both find that consumer grid-defection is highly unlikely as, 'consumers will likely have to significantly modify energy usage behaviours and accept substantial overinvestment to cover both reliability and peak demand'.

All of these futures, however, will be prevented unless linearly evolving regulatory and social structures are allowed to 'keep up' with technological change which is almost exponential in its development at present. While metering, storage and distributed energy technologies are characterised by rapidly falling cost structures, they are subject to regulatory systems which are designed for a more 'centralised' system of energy generation and distribution. At present, around $50 \%$ of an Australian residential electricity bill is comprised of a non-cost reflective 'average cost' network charge. This is preventing the development of business models which seek to deploy new storage technologies that allow customers to shift the energy produced by embedded generation (e.g. solar PV in the middle of the day) to times of high energy demand (e.g. end of the day/evening when people are using energy in their homes).

The purpose of this article is to explore what an 'ideal' Australian regulatory system may look like from a principles perspective given the profound change underway. This article assumes that three broad public policy objectives continue to be relevant for the electricity industry: competitive and affordable energy pricing; reliability and security of supply; and improved environmental outcomes (e.g. lower greenhouse gas emissions). The article is structured as follows: Section 2 outlines the current state of play in the Australian electricity market where a 'perfect storm' has led to significant change in an industry that was largely unchanged for the previous four decades; Section 3 discusses the optimal regulatory structure for keeping pace with this change; and Section 4 provides some policy principles for future regulatory evolution and concluding remarks.

\section{Current state of play - 5 years of evolution after decades of stability}

Nelson and McNeill (2016) refer to Australia being a 'perfect storm' of factors affecting energy markets. Grid prices have increased markedly over the five years to 2015 largely due to increased capital expenditure on networks. Australian residential electricity tariffs are largely structured as two part tariffs with a small fixed component and a primary 'average cost' throughput charge. Persistence with these tariffs has resulted in system capacity factors falling substantially as customers economise on consumption at times most convenient to them, not at times of system peak demand. Lower demand has resulted in higher tariffs - the classic 'death spiral' scenario. Electricity bills have increased markedly after a decade of relatively little change. This is shown in Figure 1. Note that bills in 2015 could be even higher if not for the corresponding reduction in consumption associated with own-price elasticity (the shaded area).

- Tim Nelson is Head of Economics, Policy and Sustainability at AGL Energy Ltd and an Adjunct Associate Professor at Griffith University. All views, errors and omissions are entirely the responsibility of the author. Correspondence to tanelson@agl.com.au. 
Figure 1: Electricity bills and capacity utilisation in 2002, 2009 and 2014

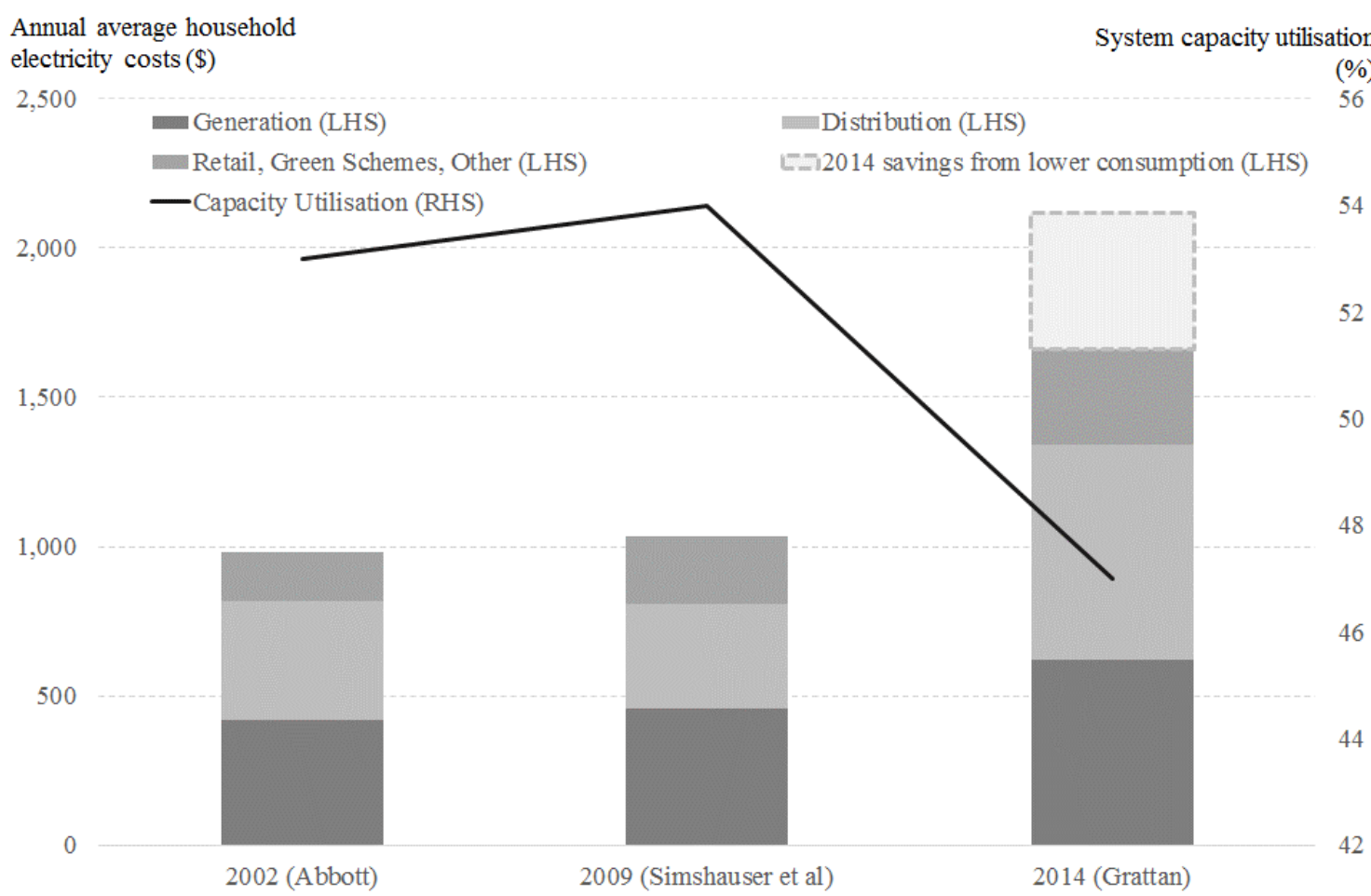

Source: Abbott (2002), Simshauser et al (2011), Grattan (2014)

Figure 1 highlights that electricity bills increased markedly between 2009 and 2014. Average household electricity bills increased from around \$1,030 p.a. in 2009 to around \$1,588 p.a. in 2015. This is despite average household usage declining over the same period from 7.48 $\mathrm{MWh}$ p.a. to just 5.88 MWh p.a. - a decline of 21 percent. Figure 1 also provides some insights into why electricity bills increased so significantly by breaking down the bill into its supply chain components. What is most observable is the very significant increase in network costs. As a contrast, between 2001 and 2005, aggregate capital expenditure on electricity networks in New South Wales and Queensland totalled just \$7 billion. In the period between 2010 and 2014, capital expenditure increased to $\$ 30$ billion (see Simshauser, Nelson and Doan, 2011). With such material growth in capital expenditure, network prices roughly doubled. Quiggin (2014) argues that poor pricing outcomes are related to excessive rates of return on monopolistic assets due to a badly designed regulatory framework. Lower underlying demand growth (or even contraction) occurred while peak demand levels were maintained or increased in individual networks, mostly driven by the uptake and subsequent use of air-conditioning. For example, in Queensland between 2007 and 2014 peak demand increased by $2.1 \%$ p.a. while underlying energy demand increased by just $0.1 \%$ p.a. 'Average cost' network tariffs increased, due to reductions in energy throughput while fixed costs have continued to be added to the electricity system to satisfy rising peak demand. Inflexibility in regulated tariff structures contributed significantly to rising gridbased electricity prices. Regulators persisted with 'average cost' pricing structures rather than shifting to Time-of-Use (ToU) or capacity based differentiated tariffs which create opportunities for consumers to benefit from energy efficiency. 
Figure 2: Annual and cumulative installation of embedded solar PV generation

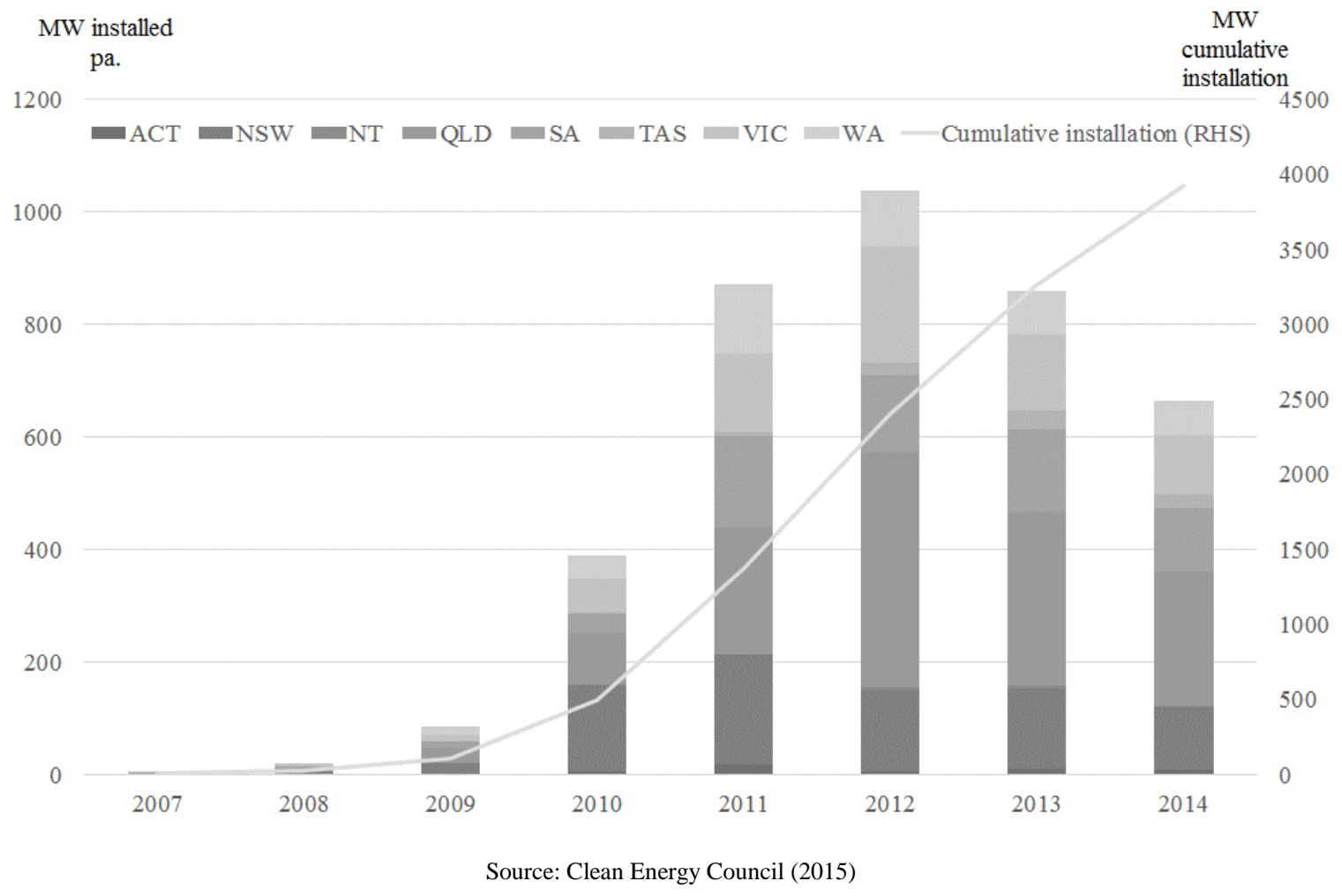

Increased grid-based prices resulted in a predictable response from consumers and firms offering partial substitutes for grid electricity. Figure 2 shows an accelerated uptake of embedded solar PV premise based generation from 2009 - the year in which electricity bills began increasing. It is important to note that capital subsidies for embedded solar PV generation units have also been used to drive uptake of these technologies - Nelson, Simshauser and Kelley (2012) have called this a form of 'outsourced taxation'. At its height, the policy environment created a payback on individual solar PV installations of just 2.1 years. However, at the time of writing most of the subsidies have been withdrawn and installation rates are still around $700 \mathrm{MW}$ per year (Clean Energy Council, 2015) - around $1.5 \%$ of total system capacity.

Another way in which the market has fundamentally changed relates to societal expectations of the nature and type of investment in large scale electricity generation. Figure 6 shows that investment in the NEM can be broken into two temporal components. First, between 1997 and 2002 a range of investments were made for the purposes of meeting increasing electricity demand. None of these investments received a capital subsidy or ongoing support in the form of 'green' certificated-based revenue streams. However, from 2003 onwards almost all investment in new generation has been supported by either capital subsidies or revenue support from certificated schemes - designed to achieve an environmental policy objective. In fact, cumulative new lower emission investment in electricity generation totals around 10,000 MW since the commencement of Australia's National Electricity Market (NEM) in 1998. 
Figure 3: Investment in large-scale generation by year and driver ${ }^{1}$

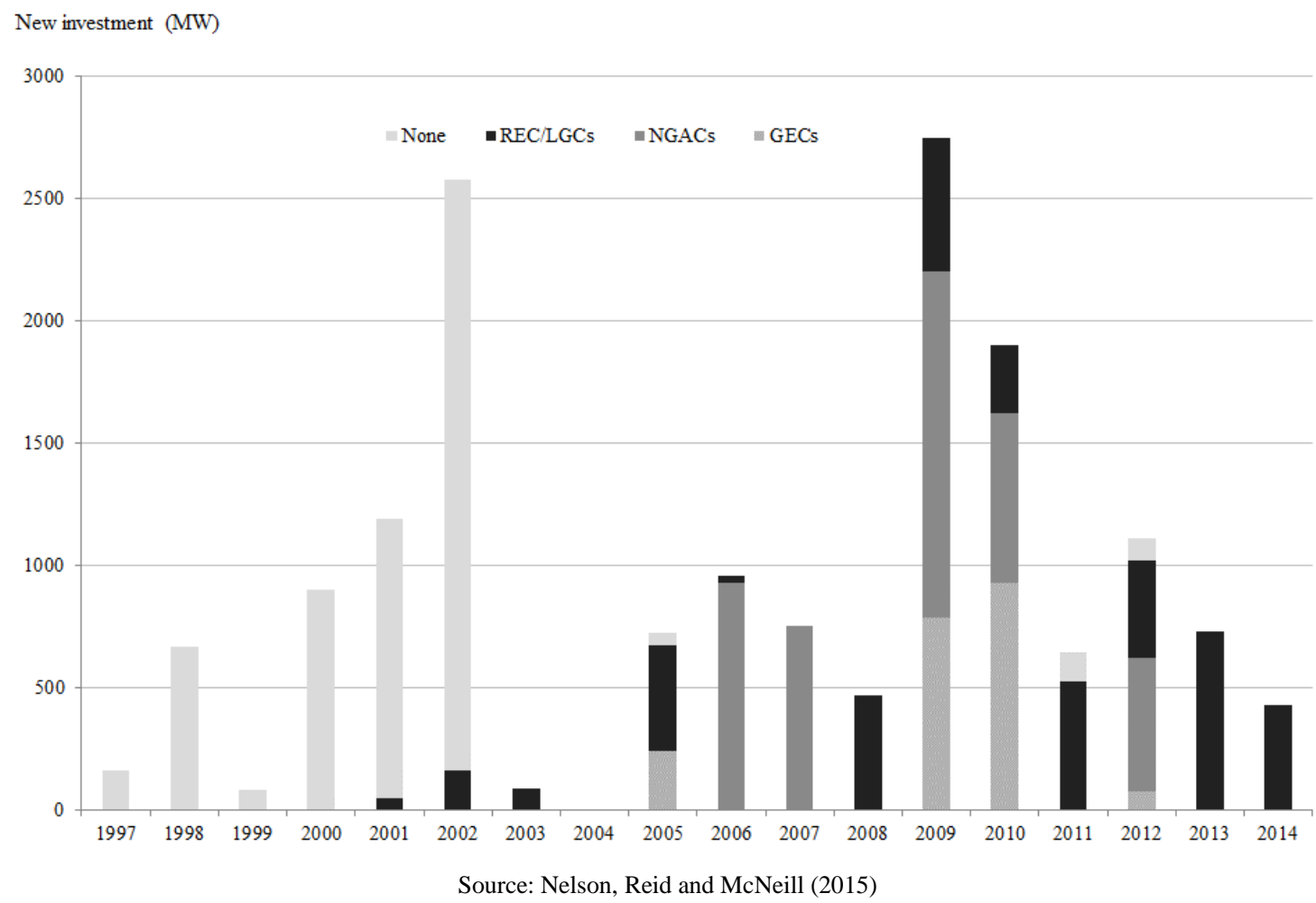

In recent years, it has become evident that the implementation of policies designed to meet societal expectations of decarbonisation is 'conflicting' with the design parameters of the energy market. Due to both barriers to exit for incumbent power stations and 'energy-only' market design, Australia's east-coast electricity market is oversupplied by around 7,000 MW - the equivalent of three large coal-fired power stations (see Nelson, Reid and McNeill, 2015). This is making investment in new renewable capacity difficult due to increasing dependency upon subsidies rather than market revenue. Furthermore, reliance upon an energy-only market (where only energy is remunerated and not capacity) is resulting in prices becoming more volatile, with long 'bust' periods followed by sudden 'spikes', due to the nature of renewable energy which is unable to be produced on demand and is often non-coincident with peak electricity demand (see Simshauser, 2014) - recall the situation in South Australia described earlier in this article.

Evolutionary economics dictates that firms must adapt to changing market or technological conditions or face extinction. Foster (2015) provides an interesting perspective on 'lock-in' within economic systems which is instructive when considering the response of the electricity industry globally to new technologies and business models. While low-cost metering, distributed generation and emerging economics of energy storage are fundamentally changing the way in which consumers view their energy supply, the regulatory and social structures underpinning the industry have been lagging behind. In this author's view, this can be explained by four characteristics of the energy supply industry globally which all result in significant inertia within the economic system: the historical stability and predictability within the industry; the capital intensive nature of energy supply; an aged workforce demographic; and the incumbent regulatory system the industry operates within - the focus of this article. Figure 4 demonstrates the first characteristic by showing how demand growth in electricity markets was linear until 2009 but is now in decline.

\footnotetext{
${ }^{1}$ REC/LGCs, NGACs, GECs are the types of subsidy certificates created by renewable and low-emission generators under existing and previous Australian environmental policies.
} 
Figure 4: Evolution of electricity industry - grinding down of grid-based demand after decades of growth

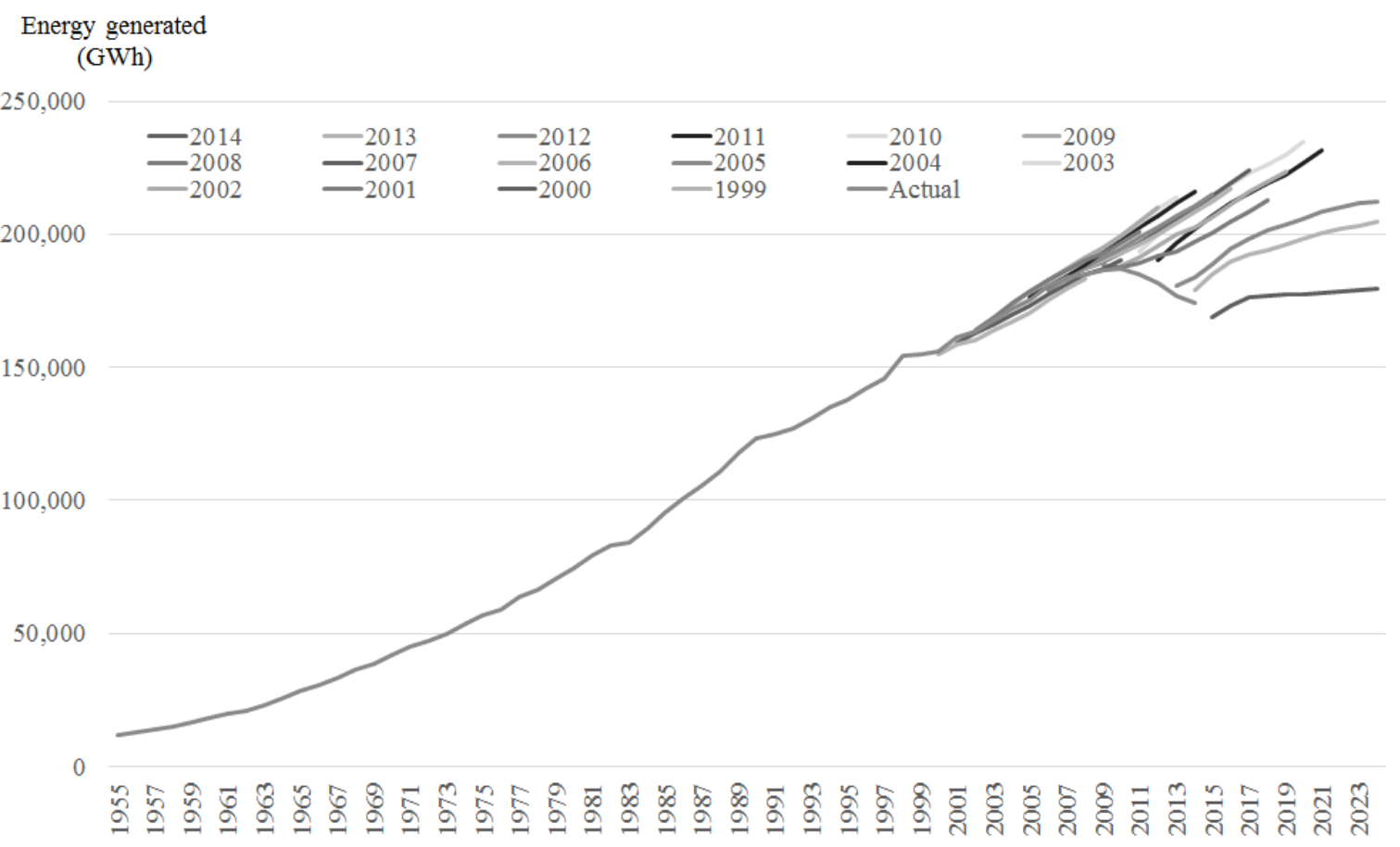

Source: AEMO (2015) and Nelson and Orton (2016)

Figure 4 shows how after five decades of uninterrupted growth, energy demand has consistently fallen since 2009. The chart also shows the independent market operator's forecast of future demand in progressive years. It is easy to note that demand forecasts have consistently been overestimated and a 'grinding-down' trend is evident. Historical stability and predictability within the electricity industry has created an economic and regulatory system that is 'locked-in' to historical trends. The development of new partial-grid substitute technologies: demand management (through digital metering); and embedded generation (solar PV), and the emergence of battery storage has resulted in change that the existing regulatory structure is designed to resist.

Simshauser and Catt (2012) note that the utilities industry globally is the third most capital intensive, after governments and financial institutions. There is substantial 'sunk' investment within electricity supply systems as the vast majority of infrastructure involves large capital investment and decadal asset lives. Accordingly, there has been a tendency within regulatory structures to 'protect' investments as disruption is seen to increase debt risk premiums associated with the sector. Higher debt risk has historically been thought to unnecessarily add to capital funding costs and disproportionately make system supply costs higher (due to the capital intensive nature of the industry) - see Simshauser and Nelson (2012) and Nelson et al (2013).

The third characteristic of the electricity industry resulting in 'inertia' and underlying resistance to the evolutionary technology entering the market is the age profile of the sector's workforce. Utilising one of the larger utilities in Australia as a proxy for the industry, Table 1 shows the significant number of employees within higher age brackets in the operations division of AGL Energy Ltd (the largest thermal generator in Australia). The age profile of this businesses operations unit is significantly different from the rest of the working population. Employees aged over 35 comprise $80 \%$ of the workforce. BCG (2015) recently noted that by 2017,50 percent of 
the Australian workforce will be Generation Y, that is born after 1980 (maximum age 35). The historical stability and predictability of the industry (recall Figure 4) no doubt attracted people with predispositions towards stability and predictability. The advent of digital metering, in-home energy management systems, distributed generation and energy storage is no doubt attracting a significantly different type of worker, with a predisposition towards embracing evolution within technologies and markets.

Table 1: Age Distribution of AGL Operations Employees

\begin{tabular}{|c|c|c|c|c|c|c|c|c|}
\hline & \multicolumn{8}{|c|}{ Age Distribution (No. of persons by age group) } \\
\hline Gender & $<20$ & $20-29$ & $30-34$ & $35-44$ & $45-54$ & $55-59$ & $60-64$ & $65+$ \\
\hline Female & 4 & 15 & 20 & 46 & 41 & 12 & 11 & 0 \\
\hline Male & 23 & 103 & 147 & 261 & 504 & 274 & 106 & 29 \\
\hline Total & 27 & 118 & 167 & 307 & 545 & 286 & 117 & 29 \\
\hline$\%$ & $2 \%$ & $7 \%$ & $10 \%$ & $19 \%$ & $34 \%$ & $18 \%$ & $7 \%$ & $2 \%$ \\
\hline
\end{tabular}

Source: AGL (2015)

Many commentators have suggested the lack of 'evolution' of the energy market is due to utilities themselves (see Parkinson, 2015; and Sioshansi, 2014 as examples of such observations). However, much of this criticism overlooks the capital intensive nature of energy supply and the evidence related to how innovation is brought to market. The OECD $(2015$, p. 36) has found that larger global firms, '..are more profitable, and more likely to patent, than other firms.'

Furthermore, the average age of these firms has been increasing since 2001. Put simply, small start-up businesses are no more likely to innovate than larger businesses unless business culture and the external market and regulatory environment facilitate such innovation.

Figure 5: Proportion of customers that could 'self-satisfy'

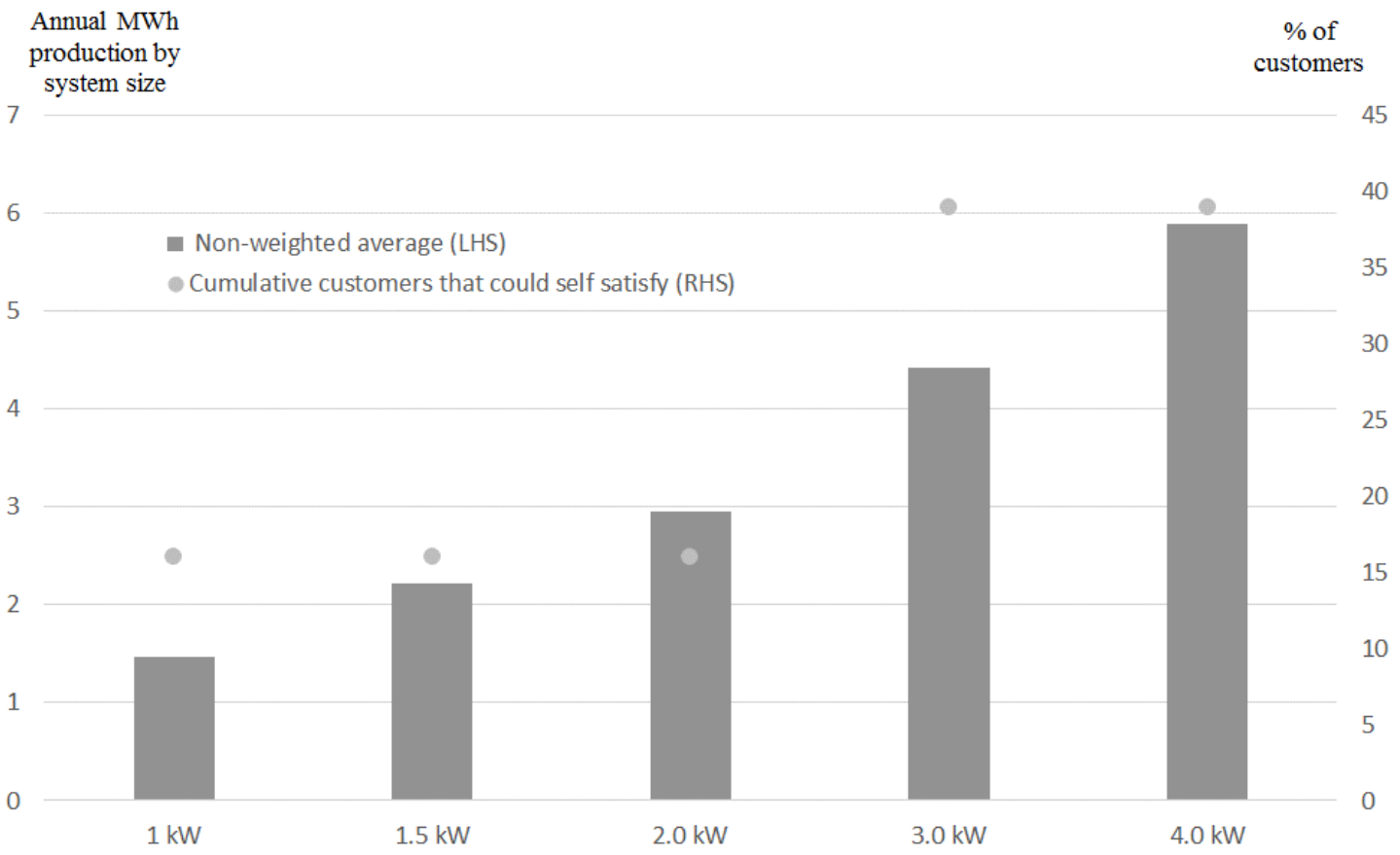

Source: Nelson and McNeill (2016)

The OECD has stated that firms - especially new entrants - should be able to experiment with new technologies and business models, and this is instructive for the Australian energy sector 
(OECD, 2015, p.4). However, there are two reasons why the sector is facing gradual change and a shift towards co-existence between distributed energy resources (DER) and the existing centralised supply of energy through a transmission and distribution grid.

The first relates to the type of innovation occurring - it is gradual and not 'revolutionary'. Gordon (2012) sums up the issue facing the electricity sector with broader observations about the US economy: the recent economic slowdown is a permanent phenomenon and that the types of innovations that took place in the first half of the 20th century (e.g. electrification) are far more significant than anything that has taken place since then (e.g. Information and Communication Technologies, ICT). Nelson and McNeill (2016) provide evidence of this in relation to electricity supply within Australia. Figure 5 shows that the proportion of customers that could 'disconnect' from their existing grid based electricity supply by substituting a large $3 \mathrm{~kW}$ or $4 \mathrm{~kW}$ DER system is at most 40 percent of the population. They note that this represents an extreme upper estimate based upon the existing consumption profile of Australian households and assuming away important real world constraints such as seasonal energy production variation. With such constraints, it is more like one in six houses.

The second issue relates to the policy and regulatory environment - the subject of the subsequent section. The OECD (2015) has stated that it, 'should enable successful firms to grow, but also let weak firms exit the market, so that scarce resources can be released to underpin the growth of the successful ones'. This article establishes a three part taxonomy to describe the current regulatory environment within Australia, which is also representative of many other electricity supply systems internationally: market design; pricing; and system roles and responsibilities. The following section will explore current settings in Australia and demonstrate that they need to evolve to 'keep up' with technology and market developments.

\section{A regulatory framework that is fit for purpose}

\subsection{Market Design}

Australia's east-coast wholesale electricity market design was established in 1998 and predicated on an energy system utilising coal and gas (thermal generation). As an 'energy-only' market, energy is paid for by electricity consumers but reliable capacity is not. In the Australian market, prices can (and do) increase from an average of around $\$ 30-\$ 40 / \mathrm{MWh}$ to $\$ 13,100 / \mathrm{MWh}$ in the space of half an hour. Prices during 'baseload' generation periods typically reflect short-run marginal costs and surplus capacity available. At intermediate and peak times, spot prices rise and reflect the increasing scarcity of capacity. Extreme peak prices must be very high so that average spot prices, calculated over any extended time period, provide a revenue stream that matches total costs (both fixed and variable) of the optimal fleet of efficient generators.

This market design may have been fit for purpose in 1998 but future investment in generation capacity is predicted to be almost solely intermittent renewable generation given recent history and existing environmental policy settings ${ }^{2}$. Such a situation is not unique to Australia. Figure 6 shows the growth in energy production by technology type between 1990 and 2013 globally. In such an environment, there is likely to be increased volatility with long time periods of "near zero' energy pricing (due to excess energy generation) and periods of extreme pricing (due to shortages of 'firm' capacity which can be reliably utilised at times of peak electricity demand). It is worth noting that estimates have been made in relation to how high the market price cap would need to be increased for generators to recover their long-run costs - if the NEM moved to being supplied by $100 \%$ renewable energy, Riesz (2014) estimates that the cap would need to increase to between $\$ 60,000$ and $\$ 80,000$ per MWh. In other words, peak pricing would be around 2,500

\footnotetext{
2 Australia's Renewable Energy Target legislation requires that around 5,000 MW of new renewable capacity must be added to the system by 2020 .
} 
times underlying prices. This volatility will be unacceptable to investors as Simshauser and Nelson (2013) have demonstrated.

Figure 6: Annual growth rates of world renewables (1990-2013)

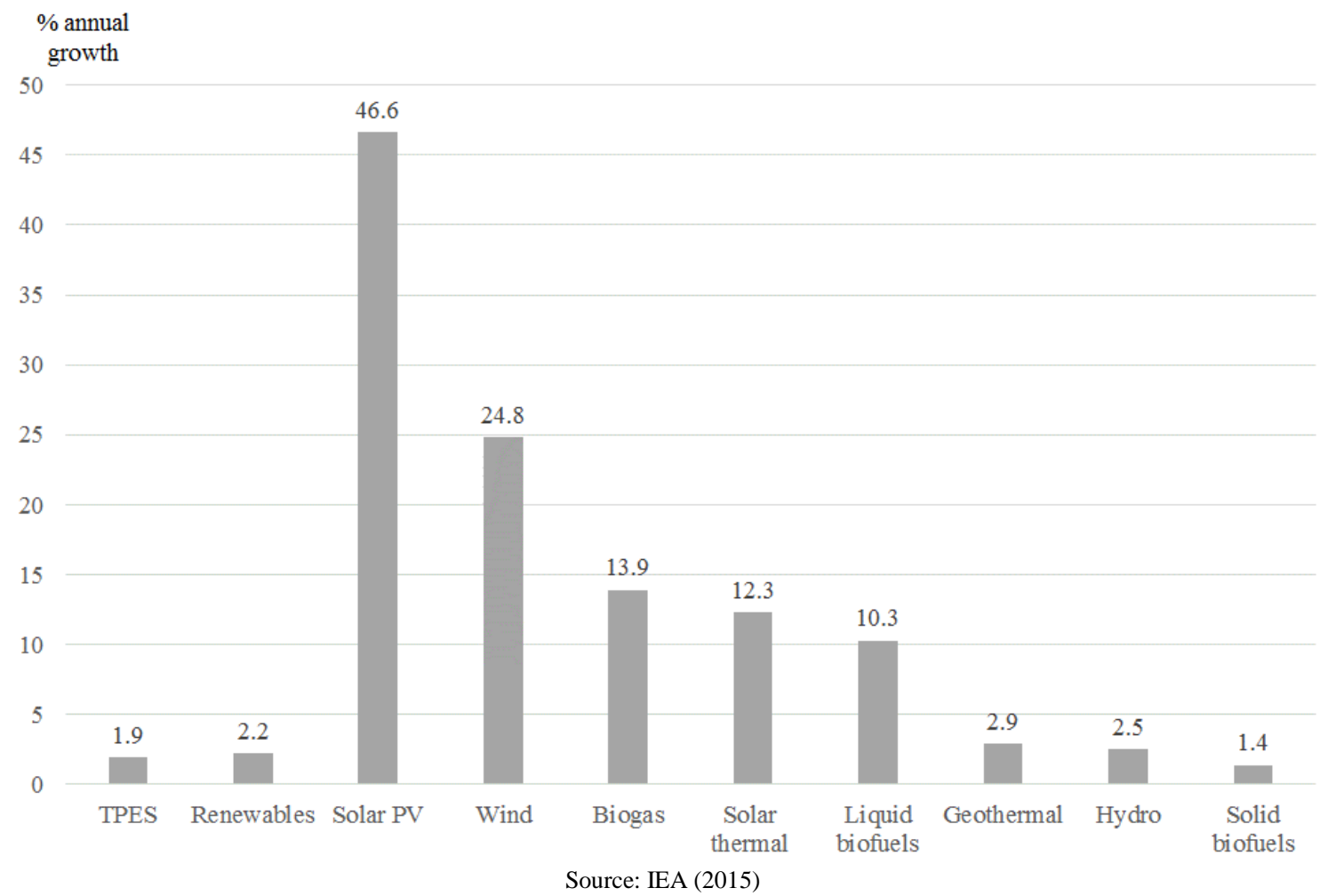

For social expectations around decarbonisation to be met, the NEM's wholesale market design will need to 'evolve'. Caplan (2014, p. 33) discusses four market constructs aimed at overcoming the 'reliability challenges that are not adequately addressed by restructured wholesale electricity markets'. According to Caplan (2014, p.33), these challenges stem from, 'retirements of coalfired generation plants, increasing levels of variable renewable resources, the need for flexible ramping capability, and increasing pressures on natural gas supplies and deliverability.' Policymakers should consider the options articulated by Caplan (2014) and Edenhofer et al (2013) with a focus on pricing the reliability value of reduced operating hours associated with generating units being made available for ramping purposes as renewable output oscillates.

\subsection{Electricity pricing}

With regard to pricing, there are two issues currently in play: the use of economic regulation generally; and pricing structures. In a market characterised by technological evolution, the regulation of pricing in markets with effective competition is unlikely to be beneficial for society. Recall in Section 2 that the continued regulation of pricing, and the lack of smart metering that facilitates appropriate time or capacity differentiated pricing signals, has resulted in average underlying costs increasing due to a divergence between peak demand (which drives system fixed costs) and underlying demand. The arguments against pricing regulation are perhaps best summarised by Yarrow (2008, p. 15) who noted that 'price regulation in competitive market situations generally harms economic efficiency.' While all States within Australia have either removed retail pricing regulation or committed to its cessation, some stakeholders are arguing that competitive markets are not delivering appropriate outcomes (as an example, see Ben-David, 2015). However, in this author's view it is more likely that this is a function of poor network tariff design and the lack of advanced metering infrastructure. 
The Australian Energy Market Commission (AEMC) has undertaken two key reform processes that could be said to be attempting to facilitate evolution, rather than stifle it. The first is the deregulation of metering whereby all metering services for residential consumers are now contestable. This should assist with both improving service quality (see Nelson and Simshauser, 2014) and pricing efficiency. The second of these changes is the requirement that regulated electricity networks establish prices that are 'cost-reflective'. There is a wealth of literature in the Australian context about the benefits of more cost-reflective pricing for overcoming the issues documented in Section 2 - see Simshauser and Downer (2012), Simshauser and Nelson (2014) and Nelson and Orton (2013) as examples.

As a result of the AEMC reform process, networks are establishing new tariffs that will be effective for creating an arbitrage opportunity for individual customers. Table 2 outlines the tariffs that could be implemented and where networks are proposing to use them. The adoption of new tariff design requires the approval of the Australian Energy Regulator (AER).

Table 2: Tariff design types and proposed adoption by Australian network businesses

\begin{tabular}{|c|c|c|}
\hline Tariff Type & Description & Emerging Examples \\
\hline Inclining block & $\begin{array}{c}\text { Prices increase in 'blocks' as energy } \\
\text { consumption increases }\end{array}$ & None \\
\hline Declining block & $\begin{array}{c}\text { Prices decrease in 'blocks' as energy } \\
\text { consumption increases }\end{array}$ & NSW networks \\
\hline Peak demand & $\begin{array}{c}\text { Price based upon maximum demand } \\
\text { recorded in a particular time period }\end{array}$ & $\begin{array}{c}\text { VIC and QLD } \\
\text { networks }\end{array}$ \\
\hline Peak demand* & $\begin{array}{r}\text { Price based upon maximum demand } \\
\text { recorded any time }\end{array}$ & Limorks \\
\hline ToU & $\begin{array}{r}\text { Energy prices vary based upon time of day } \\
\text { energy is consumed }\end{array}$ & None \\
\hline FDR & $\begin{array}{c}\text { Pricing based upon first derivative of } \\
\text { demand (see Nelson and Orton, 2013) }\end{array}$ & Limited \\
\hline
\end{tabular}

Source: Network submissions to AER

Networks in Queensland, South Australia and Victoria are shifting away from 'average cost' tariffs to demand based tariffs. Solar output is not coincident with peak demand. Introducing demand tariffs would ensure that a household would pay network charges to reflect their use of the network irrespective of the output produced by their solar PV system. Around one million Australian households now have solar PV on their roof and each of these consumers will view their investment in solar as a 'sunk cost'. With the shift to demand tariffs, there will be a clear investment case for any battery technology that allows the consumer to shift the output of their solar PV system to the time of their peak demand. Given current knowledge of how technology may evolve, these pricing structures (due to be introduced in 2017) appear to be appropriate. 
Importantly, electricity prices in Australia are forecast to decline in real terms as regulators reduce revenue caps and revise down Weighted Average Cost of Capital (WACC) allowances between 2015 and 2020. Orton and Nelson (2015) estimate that electricity bills in 2020 may be lower than today in real terms due to both declining pricing and increased focus on energy efficiency and electricity productivity (see the recently released Australian Government National Energy Productivity Plan, 2015). These developments are important as consumers will be able to choose their own energy futures with the adoption of smart devices (e.g. in-home displays, batteries and solar PV) driven by allocative efficient pricing or continue to rely solely on gridbased supply - depending upon their circumstances.

A key unresolved issue will relate to the treatment of any 'stranded assets' within electricity networks. If consumers utilise increased distributed energy resources, the use of the existing network may decline. This presents policy makers with a dilemma. It could be argued that network assets should be written down in value if they are underutilised with resultant declines in pricing for consumers. Alternatively, policy makers may contend that the operators of such networks were prevented from earning monopolist profits in the past through economic regulation and should therefore be insulated from being exposed to competitive market losses. Either way, the world of policy and regulation will need to 'evolve and adapt' in the same way that technology and consumer preferences are. Crawford (2015) provides some interesting insights that policy makers may wish to consider in this context.

\subsection{Rules and responsibilities of market participants}

One of the most important and unresolved issues in relation to a regulatory framework that is fit for purpose for recently introduced and emerging technologies relates to roles and responsibilities. In particular, there is an increasingly 'blurry' line between the roles of competitive markets and regulated networks.

The current regulatory framework is documented within the National Electricity Rules (NER) and would no doubt be similar in many restructured electricity markets around the world. Chapter 5A of the NER establishes the processes for connecting distributed generation and storage to a local distribution network. Embedded generation is deemed to be a 'generation unit' while storage is classified as both a 'generation unit' and a 'load'. The process depends upon a number of factors including, "whether the DNSP is satisfied that its network can accommodate the connection of the device'. There is currently no standardised process across the NEM jurisdictions for this. Under the National Electricity Rules (NER), distributed solar PV and storage are exempt from requiring registration with the Australian Energy Market Operator (AEMO). However, these units must sell output 'off-market' to a local retailer or customer at the connection point.

This is presenting consumers with challenges. In some instances consumers are being informed that they cannot install solar systems of a certain size or install a system at all. Interestingly, there is little evidence that networks have ever prevented customers installing large energy consuming devices (e.g. air-conditioning). Public policy will need to evolve with consumer preferences. At the very least, society would expect that consumers have a 'right' to install a solar system that produces sufficient energy for their own use. This 'right' would need to be limited to selfconsumption to ensure economic efficiency and equity are not compromised.

Similarly, the recently deregulated metering market presents society and policy makers with complex challenges. Emerging evidence indicates that networks are refusing to facilitate removal of old technology meters (these 'Type 6' accumulation meters are owned by the networks) even where a customer has agreed with another party to have a digital meter installed. No doubt networks have a legitimate role in ensuring public safety as sub-standard equipment and poorly installed devices may compromise public safety but policy makers will need to be careful in 
ensuring that information asymmetry is not being used to prevent legitimate deployment of new technologies. This will require greater scrutiny of network activities by regulators with potential penalties for stifling innovation in the deployment of new technologies (such as electricity meters) that allow consumers to take more control of their energy usage.

Perhaps the most confusion around the role of regulated networks is in installing behind the meter or 'at the substation' style investments in battery storage. In this author's view, it is nonsensical to assume that networks would continue to have new technologies added to their Regulated Asset Base (RAB or assets on their balance sheets) given the discussion around asset stranding of existing assets and the fierce resistance to it as a concept (see Crawford, 2015). At the very least, networks should be compelled to go to competitive tender for services that are constable.

Importantly, in its Discussion Paper, the AEMC (2015, p. ii) has found that it is, 'therefore of the view that for the purposes of network regulation, storage should be considered a contestable service. Network businesses should only be allowed to own storage behind the meter through an effectively ring-fenced affiliate that separates this activity from the provision of regulated network services'. This is not really a new position for regulators to be adopting. Established in 2002, the Australian Competition and Consumer Commission (ACCC) Transmission RingFencing Guidelines state that network providers 'that supply ring-fenced services (that is, prescribed services) must not carry on a related business (defined as generation, distribution and electricity retail activities)'.

Retailer licence exemptions have also become a prominent fixture within the market. Recall from earlier in this article that electricity is regarded as an essential service. To sell electricity, a participant must have a retail licence. These licences place obligations on retailers to ensure that customers are not unfairly disconnected from their energy supply and that all efforts (including payment plans) are made to ensure that customers are able to pay their electricity bills. In the past two years, new business models have developed for selling solar PV through Power Purchasing Agreement (PPA) style agreements. These arrangements effectively act as an alternative to gridsupply whereby the household acquiesces to a distributed energy system being installed at their premises and they pay an ongoing fee for consuming energy it generates. Many of these businesses have been granted retail licence exemptions. This presents certain problems as the essential service protections provided through retail licences will no longer apply for households that enter into such arrangements. This requires further thought from policy makers - it could be that society no longer views energy as an essential service. However, in this author's view it is more likely that these retail licence exemptions may need to be rethought if the essential service policy objective is to be fulfilled in the future.

Roles and responsibilities are increasingly being clearly defined with an expectation that competitive markets should be used to facilitate the evolution of customer preferences and technology. During 2015 and 2016, the Australian Energy Regulator (AER) is establishing revised ring-fencing guidelines. This process will be critically important for ensuring that the regulatory and policy framework 'keeps pace' with the energy market evolution underway. 


\section{Policy principles and concluding remarks}

Policy makers need to consider how the electricity market is evolving and the most appropriate policy framework required to give effect to the overarching objectives society expects delivered: competitive and affordable energy pricing; reliability and security of supply; and improved environmental outcomes (e.g. lower greenhouse gas emissions). This will require an assessment of the way in which the evolving nature of energy supply fits into the future of the home, society and the economy. Smith and MacGill (2016) make the salient point:

At high income levels, like those of the electricity customer of the future, grid electricity may become an inferior good, with usage falling with income as more expensive new appliances and dwelling are inherently more energy efficient and solar + storage may be preferred as a lifestyle choice rather than simply a cost effectiveness decision.

The policy and regulatory framework has been slow to respond to the evolution of consumer preferences and technology. Due in part to inflexible regulatory frameworks, retail electricity prices doubled in Australia over the past five years. System capacity utilisation has fallen resulting in higher average costs for all energy consumers. However, there is emerging evidence that policy makers and regulators are identifying where change is required to facilitate, rather than stymie, evolution. This article has argued that at least three areas require continued focus: ensuring the appropriate wholesale market design is in place to facilitate investment in a generation fleet that is low-emissions and reliable; allocative pricing for network and retail pricing; and establishing clear roles and responsibilities within the regulatory framework that ensures competition is facilitated and not impeded.

In this author's view, the following six policy principles would be worth establishing in the current environment to facilitate policy and regulatory change into the future:

Contestability, rather than regulation (in the absence of market failure), should be the starting point for development of roles and responsibilities within the energy supply chain.

- $\quad$ Competitive neutrality should be a cornerstone of policy development. Where entities have a competitive advantage bestowed upon them by regulation, appropriate ring-fencing should be in place to ensure that information asymmetry is not used to the detriment of consumers.

- $\quad$ National consistency should be prioritised. Australia is a Federal system of government and regulatory arbitrage is a key disadvantage of fragmented and differentiated policies across jurisdictional borders.

- $\quad$ Allocative efficient (cost reflective) pricing should be mandated where entities are regulated.

- $\quad$ Appropriate consumer protections should be in place which reflect society's expectations around the role of energy as an essential service. These protections should apply uniformly to participants where energy supply is the primary focus of their interaction with the consumer.

- $\quad$ Technology standards should be robust and reflect guaranteed safe use of energy within the home and minimum levels of performance. 
Future energy markets will be considerably more customer-focused and decentralised than they are today. It is important that regulatory settings that were developed for a fundamentally centralised energy system with clearly defined market participants (generators, networks, retailers, consumers) are reviewed to ensure they are suitable for the future. To facilitate this market transformation, regulatory frameworks need to be technology-neutral and flexible to support a range of innovative new business models. Most importantly these frameworks should be focused on users of energy. As Smith and MacGill (2016) state, 'Technologies will not shape the utility of the future - customers will.' This has always been true of markets in transition new technology is only adopted if customers deem it worthwhile.

\section{References}

Abbott, M. (2002), 'Completing the introduction of competition into the Australian electricity industry', Economic Papers, Vol. 21, pp.1-13.

AGL. (2015), 2015 AGL Sustainability Report, AGL Publication, Sydney.

Australian Energy Market Commission: AEMC. (2015), Integration of Storage: Regulatory Implications, Draft report, 9 October 2015, Sydney.

Australian Energy Market Operator: AEMO. (2015), National Electricity Forecasting Report, AEMO Publication, Melbourne.

BCG. (2015), Presentation to AGL Energy, December 2015, Sydney.

Ben-David, R. (2015), 'If the retail energy market is competitive then is Lara Bingle a Russian cosmonaut?', Presentation to the NEM Future Forum, 25 June 2015, Sydney.

Caplan, E. (2014), 'Supplementing competition: direct payment constructs within restructured markets', The Electricity Journal, Vol. 27, No. 1, pp. 33-41.

Clean Energy Council. (2015), Clean Energy Australia, Clean Energy Council Publication, Melbourne.

Crawford, G. (2015), 'Network depreciation and energy market disruption: Options to avoiding passing costs down the line', Economic Analysis and Policy, Vol. 48, pp. 163-171.

CSIRO. (2015), 'The CSIRO's findings - Electricity storage technologies and their applications', Presentation to AEMC Energy Storage Public Forum, 18 June 2015, Sydney.

CSIRO. (2014), Change and choice: The Future Grid Forum's analysis of Australia's potential electricity pathways to 2050, CSIRO Publication, Canberra.

Edenhofer, O., Hirth, L., Knopf, B., Pahle, M., Schlömer, S., Schmid, E., and Ueckerdt, F. (2013), 'On the economics of renewable energy sources', Energy Economics, Vol. 40, Supplement 1, pp. S12-S23.

Energy Supply Association of Australia: esaa. (2015), Electricity Gas Australia, esaa Publication, Melbourne.

Foster, J. (2015), 'Lock-in and uncertainty in complex economic systems: developing an alternative to conventional economic analysis', Presentation to Managing the transition to a 
sustainable economy: Some insight from an evolutionary perspective, Griffith University, 22 October 2015, Brisbane.

Gordon, R. (2012), 'Is U.S. Economic Growth Over? Faltering Innovation Confronts the Six Headwinds', NBER Working Papers, No. 18315.

Grattan Institute. (2014), Fair pricing for power, Grattan Institute Publication, Melbourne.

Nelson, J. and Simshauser, P. (2013), 'Is the Merchant Power Producer a broken model', Energy Policy, Vol. 53(C), pp. 298-310.

Nelson, T. (2015), ‘Australian Climate Change Policy - Where To From Here?', Economic Papers, Vol. 34, No. 4, pp. 257-272.

Nelson, T. and Orton, F. (2016), 'Optimising demand response in Australia's National Electricity Market', Australian Economic Review, Article-in-press.

Nelson, T. and McNeill, J. (2016), 'The role of the utility and pricing in the transition', in Future of Utilities: Utilities of the Future, Edited by Sioshansi, F.S., Elsevier.

Nelson, T., Reid, C. and McNeill, J. (2015), 'Energy-only markets and renewable energy targets: Complementary policy or policy collision?', Economic Analysis and Policy, Vol. 46, pp.25-42.

Nelson, T. and Orton, F. (2013), "A new approach to congestion pricing in electricity markets: Improving user pays pricing incentives”, Energy Economics, Vol.40, pp. 1-7.

Nelson, T., Nelson, J., Ariyaratnam, J. and Camroux, S. (2013), “An analysis of Australia's Large Scale Renewable Energy Target: restoring market confidence”, Energy Policy, Vol. 62, pp. 386400 .

Nelson, T., Simshauser, P. and Nelson, J. (2012), 'Queensland Solar Feed-In Tariffs and the Merit-Order Effect: Economic Benefit, or Regressive Taxation and Wealth Transfers?', Economic Analysis and Policy, Vol. 42 No. 3, pp. 277-301.

OECD. (2015), The Future of Productivity, OECD Publication, Paris.

Orton, F. and Nelson, T. (2015), 'Relief in sight: Why residential electricity costs in Eastern Australia may fall between 2015 and 2020', Economic Analysis and Policy, Vol. 48, pp. 57-70.

Riesz, J. (2014), 'Will the NEM energy-only market work with high renewables?', CSIRO FutureGrid Conference Presentation, February.

Simshauser, P. (2014), 'From first place to last: Australia's policy-induced energy market death spiral', Australian Economic Review, Vol. 47, No. 4, pp. 540-62.

Simshauser, P. and Nelson, T. (2014), 'The Consequences of Retail Electricity Price Rises: Rethinking Customer Hardship', The Australian Economic Review, Vol. 47, No. 1, pp. 13-43.

Simshauser, P. and Catt, A. (2012), 'Dividend Policy, Energy Utilities and the Investment Megacycle', The Electricity Journal, Vol. 25, No. 4, pp. 63-87.

Simshauser, P. and Downer, D. (2012), 'Dynamic Pricing and the Peak Electricity Load Problem', The Australian Economic Review, Vol. 45, No. 3, pp. 305-324. 
Simshauser, P. and Nelson, T. (2012), 'Carbon taxes, toxic debt and second-round effects of zero compensation: the power generation meltdown scenario', Journal of Financial Economic Policy, Vol. 4, No. 2, pp.104-127.

Simshauser, P., Nelson, T. \& Doan, T. (2011), 'The Boomerang Paradox, Part I: How a Nation's wealth is creating fuel poverty', The Electricity Journal, Vol. 24, Issue 1, pp. 72-91.

Smith, R. and MacGill, I. (2016), 'The future of utility customers and utility customers of the future', in Future of Utilities: Utilities of the Future, Edited by Sioshansi, F.S., Elsevier.

Yarrow, G. (2008), Report on the Impact of Maintaining Price Regulation, Regulatory Policy Institute, Oxford. 